\title{
Environmental Management System Plan
}

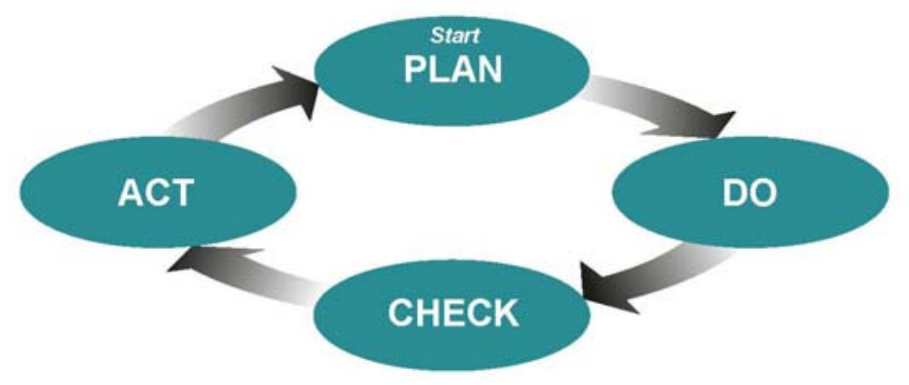

\author{
Prepared by: \\ Environment, Health, and Safety Division \\ Environmental Services Group
}

March 2009

Revision 4

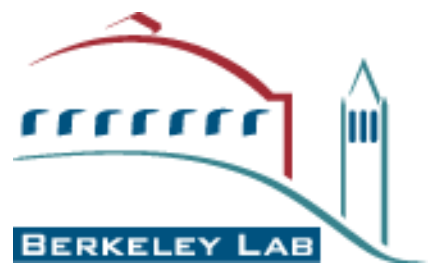

Ernest Orlando Lawrence Berkeley National Laboratory

Berkeley, CA 94720

This work was supported by the U.S. Department of Energy under Contract No. DE- AC02-05CH11231. 


\section{Disclaimer}

This document was prepared as an account of work sponsored by the United States Government. While this document is believed to contain correct information, neither the United States Government nor any agency thereof, nor The Regents of the University of California, nor any of their employees, makes any warranty, express or implied, or assumes any legal responsibility for the accuracy, completeness, or usefulness of any information, apparatus, product, or process disclosed, or represents that its use would not infringe privately owned rights. Reference herein to any specific commercial product, process, or service by its trade name, manufacturer, or otherwise, does not necessarily constitute or imply its endorsement, recommendation, or favoring by the United States Government or any agency thereof, of The Regents of the University of California. The views and opinions of authors express herein do not necessarily state or reflect those of the United States Government or any agency thereof or The Regents of the University of California. 


\section{Table of Contents}

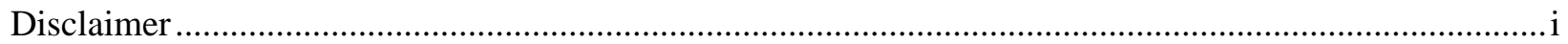

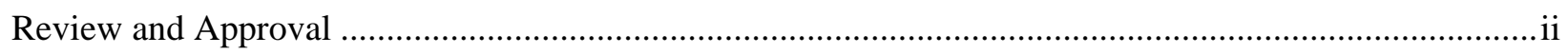

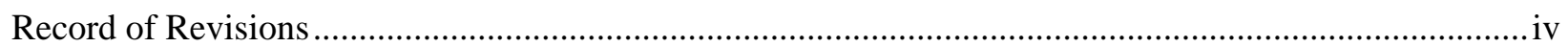

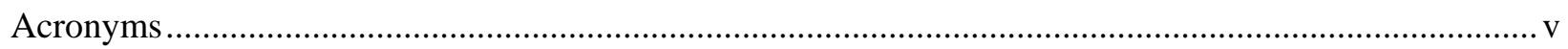

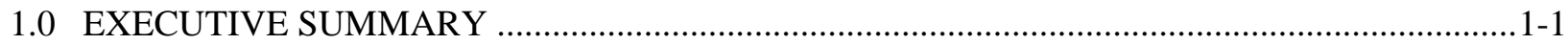

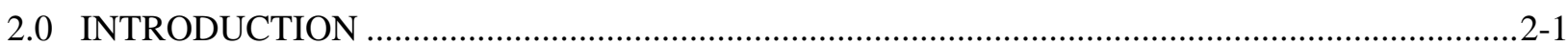

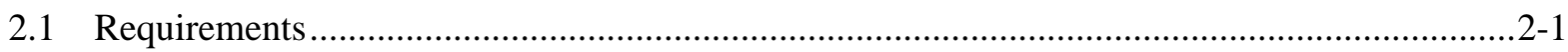

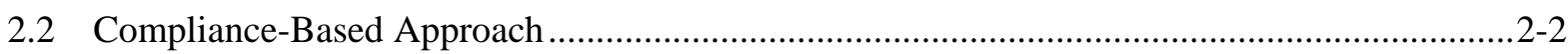

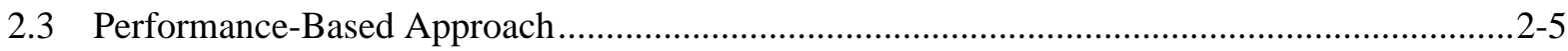

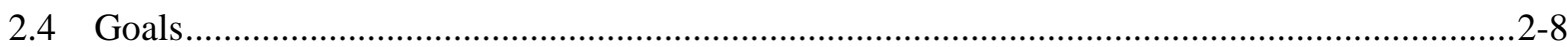

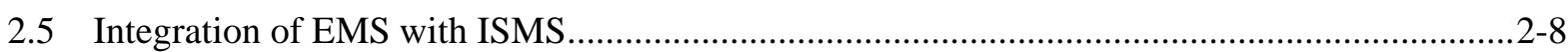

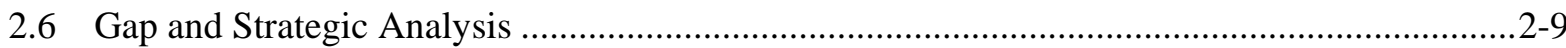

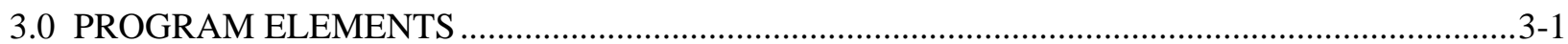

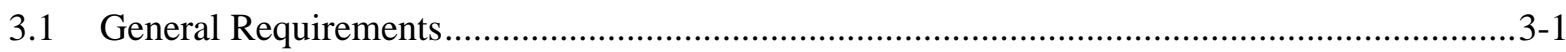

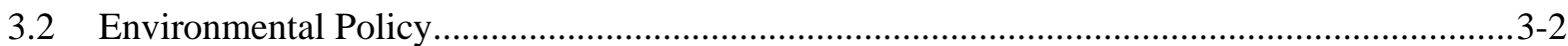

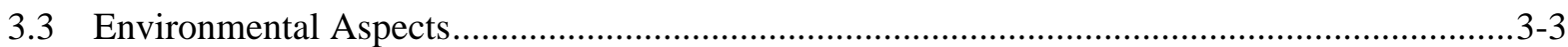

3.4 Legal and Other Requirements ................................................................................................

3.5 Objects, Targets, and Environmental Management Programs ....................................................

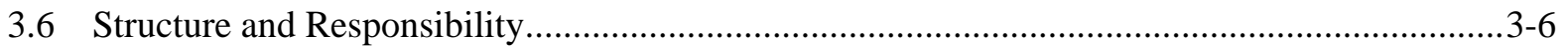

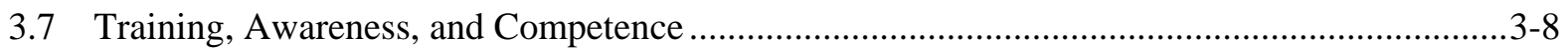

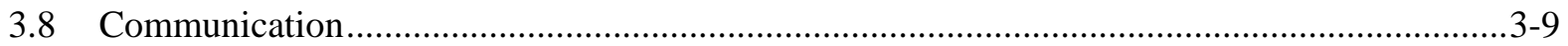

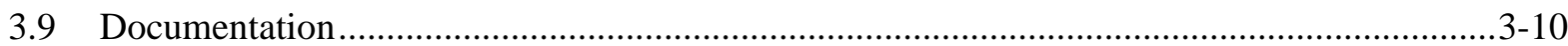

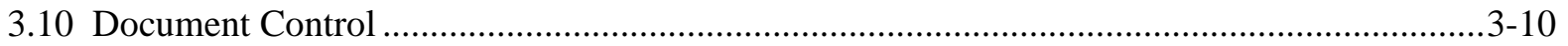

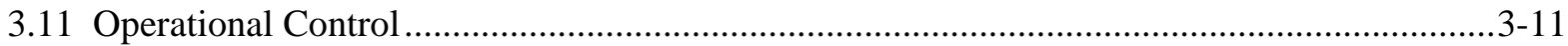

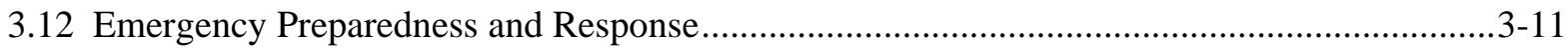

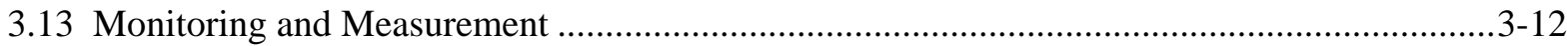

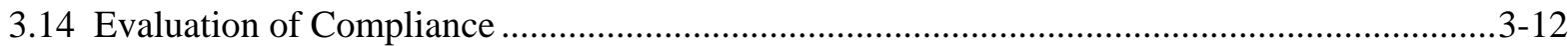

3.15 Nonconformance, Corrective Action, and Preventive Action ................................................3-13

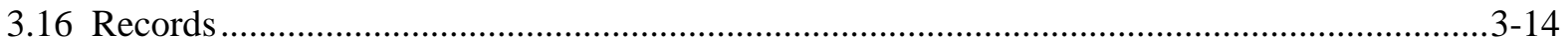

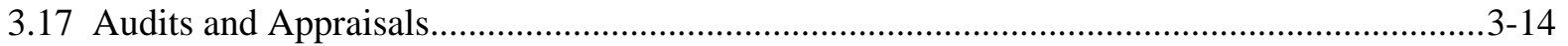

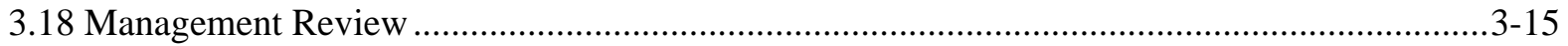

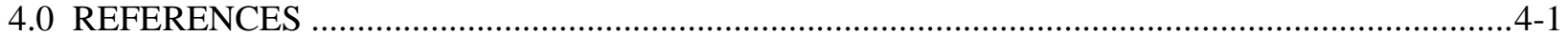




\section{Record of Revisions}

\begin{tabular}{|l|l|l|l|}
\hline Revision \# & Description & Section(s) & Date of Revision \\
\hline Rev. 0 & Original & All & September 2004 \\
\hline Rev. 1 & $\begin{array}{l}\text { Expanded sign-off; minor reorganization of } \\
\text { layout; added implementing procedures and } \\
\text { environmental management programs as } \\
\text { appendices }\end{array}$ & $\begin{array}{l}\text { Appendices } \\
\text { A \& B }\end{array}$ & March 2005 \\
\hline Rev. 2 & Minor revisions & All & August 2005 \\
\hline Rev. 3 & $\begin{array}{l}\text { Core Team adjustments; expanded program } \\
\text { elements from 6 to 17 to account for all ISO } \\
\text { 14001 elements }\end{array}$ & 3 & July 2008 \\
\hline Rev. 4 & $\begin{array}{l}\text { Incorporate requirements of DOE Orders } \\
\text { 430.2B and 450.1A; expanded elements from } \\
17 \text { to 18 }\end{array}$ & All & March 2009 \\
\hline
\end{tabular}




\section{Acronyms}

$\begin{array}{ll}\text { C } & \text { Control/Maintain (EMP classification) } \\ \text { CATS } & \text { Corrective Action Tracking System } \\ \text { DOE } & \text { Department of Energy } \\ \text { ECAAP } & \text { Environmental Compliance Audit and Assessment Program } \\ \text { EH\&S } & \text { Environment, Health \& Safety (the organizational division) } \\ \text { ES\&H } & \text { Environment, Safety \& Health (the discipline) } \\ \text { ESG } & \text { Environmental Services Group } \\ \text { EMP } & \text { Environmental Management Program } \\ \text { EMS } & \text { Environmental Management System } \\ \text { FY } & \text { Fiscal Year } \\ \text { I } & \text { Improve (EMP classification) } \\ \text { ISMS } & \text { Integrated Safety Management System } \\ \text { ISO } & \text { International Organization for Standardization } \\ \text { LBNL } & \text { Lawrence Berkeley National Laboratory } \\ \text { OCA } & \text { Office of Contract Assurance } \\ \text { OIA } & \text { Office of Institutional Assurance } \\ \text { OQMP } & \text { Operating and Quality Management Plan } \\ \text { PEMP } & \text { Performance Evaluation Measurement Plan } \\ \text { S } & \text { Study/lnvestigate (EMP classification) } \\ \text { SER } & \text { Site Environmental Report }\end{array}$




\section{0 \\ Executive Summary}

Executive Order 13423, Strengthening Federal Environmental, Energy, and Transportation Management ${ }^{\underline{1}}$ establishes the policy that Federal agencies conduct their environmental, transportation, and energyrelated activities in a manner that is environmentally, economically and fiscally sound, integrated, continually improving, efficient, and sustainable. The Department of Energy (DOE) has approved DOE Order 450.1A, Environmental Protection Program ${ }^{2}$ and DOE Order 430.2B, Departmental Energy, Renewable Energy and Transportation Management ${ }^{3}$ as the means of achieving the provisions of this Executive Order.

DOE Order 450.1A mandates the development of Environmental Management Systems (EMS) to implement sustainable environmental stewardship practices that:

- Protect the air, water, land, and other natural and cultural resources potentially impacted by facility operations,

- Meet or exceed applicable environmental, public health, and resource protection laws and regulations, and

- Implement cost-effective business practices.

In addition, the DOE Order 450.1A mandates that the EMS must be integrated with a facility's Integrated Safety Management System (ISMS) established pursuant to DOE P 450.4, Safety Management System Policy. ${ }^{4}$

DOE Order 430.2B mandates an energy management program that considers energy use and renewable energy, water, new and renovated buildings, and vehicle fleet activities. The Order incorporates the provisions of the Energy Policy Act of $2005^{\frac{5}{}}$ and Energy Independence and Security Act of 2007..$^{6}$ The Order also includes the DOE's Transformational Energy Action Management initiative, which assures compliance is achieved through an Executable Plan that is prepared and updated annually by Lawrence Berkeley National Laboratory (LBNL, Berkeley Lab, or the Laboratory) and then approved by the DOE Berkeley Site Office. At the time of this revision to the EMS plan, the FY2009 LBNL Sustainability Executable Plan ${ }^{7}$ represented the most current Executable Plan.

These DOE Orders and associated policies establish goals and sustainable stewardship practices that are protective of environmental, natural, and cultural resources, and take a life cycle approach that considers aspects such as:

- Acquisition and use of environmentally preferable products

- Electronics stewardship 
- Energy conservation, energy efficiency, and renewable energy

- Pollution prevention, with emphasis on toxic and hazardous chemical and material reduction

- Procurement of efficient energy and water consuming materials and equipment

- $\quad$ Recycling and reuse

- Sustainable and high-performance building design

- Transportation and fleet management

- Water conservation

LBNL's approach to sustainable environmental stewardship required under Order 450.1A poses the challenge of implementing its EMS in a compliance-based, performance-based, and cost-effective manner. In other words, the EMS must deliver real and tangible business value at a minimal cost. The purpose of this plan is to describe Berkeley Lab's approach for achieving such an EMS, including an overview of the roles and responsibilities of key Laboratory parties.

This approach begins with a broad-based environmental policy consistent with that stated in Chapter 11 of the LBNL Health and Safety Manual ${ }^{\underline{8}}$ (PUB-3000). This policy states that Berkeley Lab is committed to the following:

1. Complying with applicable environmental, public health, and resource conservation laws and regulations.

2. Preventing pollution, minimizing waste, and conserving natural resources.

3. Correcting environmental hazards and cleaning up existing environmental problems, and

4. Continually improving the Laboratory's environmental performance while maintaining operational capability and sustaining the overall mission of the Laboratory.

A continual cycle of planning, implementing, evaluating, and improving processes will be performed to achieve goals, objectives, and targets that will help LBNL carry out this policy. Each year, environmental aspects will be identified and their impacts to the environment will be evaluated. Objectives and targets will be developed (or updated) for each aspect that is determined to have a significant impact. Environmental Management Programs (EMPs) will be prepared (or updated) to document actions necessary for reducing certain environmental impacts. Each EMP will identify responsible parties and associated target deadlines for each action.

Quarterly, environmental programs will be reviewed for compliance issues and effectiveness. Annually, an internal assessment will be performed to evaluate the progress of the EMS, and LBNL senior management will review the results. In addition, at least once every 3 years a third-party audit will be performed to validate that the EMS is being implemented according to plan. 
This Plan is integrated with the Laboratory's ISMS as described in the LBNL Integrated Environment, Health and Safety Management Plan ${ }^{9}$ (PUB-3180). To the extent that it is practical, ISMS processes will be used to support environmental performance improvement. In other cases, new processes will be developed to support the LBNL EMS and these will be integrated with the LBNL ISMS. This approach will allow LBNL to develop an EMS that is cost-effective and to focus resources on those activities with the highest potential environmental benefits.

The LBNL EMS reflects the eighteen element of the International Organization for Standardization (ISO) 14001:2004(E), Environmental Management Systems Requirements with Guidance for Use,,$^{10}$ but does not include ISO 14001 certification. Such certification is not a DOE requirement and does not provide a sufficient business value to the Berkeley Lab. Certification under ISO 14001 is most beneficial to firms or organizations that produce a product or service intended directly for the global marketplace. ISO 14001 certification imposes extensive requirements for preparing detailed documentation and creating processes that have little environmental benefit and are not cost-effective for the Laboratory. Meeting all of the requirements of ISO 14001 would force a shift in resources away from activities that could be used to improve environmental performance toward performing those that have relatively little value. As called for in DOE Order 450.1A, the LBNL EMS reflects the elements and framework found in the ISO Standard. Section 3 of this EMS Plan describes how each one of the eighteen elements in the ISO Standard is addressed, including reference to any procedure, plan, or process that implements these elements. 


\section{0 \\ Introduction}

\section{$2.1 \quad$ REQUIREMENTS}

Executive Order 13423, Strengthening Federal Environmental, Energy, and Transportation Management establishes the policy that Federal agencies conduct their environmental, transportation, and energyrelated activities in a manner that is environmentally, economically and fiscally sound, integrated, continually improving, efficient, and sustainable. The overarching policy and directive as expressed in this Executive Order is:

"It is the policy of the United States that Federal agencies conduct their environmental, transportation, and energy-related activities under the law in support of their respective missions in an environmentally, economically and fiscally sound, integrated, continuously improving, efficient, and sustainable manner."

DOE Order 450.1A, Environmental Protection Program, and DOE Order 430.2B, Departmental Energy, Renewable Energy and Transportation Management, established requirements for all DOE facilities necessary to implement Executive Order 13423. Both Orders direct DOE contractors to implement an Environmental Management System as the primary management approach for addressing aspects of environmental, energy, water, and transportation activities, along with establishing objectives and targets to ensure implementation and collection, analysis, and reporting of information to measure performance. The EMS is not a stand-alone environmental program, but a framework within which existing and new organizational responsibilities, programs, and activities are linked. DOE Orders 450.1A and 430.2B also mandate that the EMS be integrated with the Laboratory’s existing ISM System.

The scope of the EMS must be far reaching, aimed at protecting public health and the environment by including the more traditional environmental compliance programs, such as air and water quality, as well as less traditional programs, such as wildland fire management, assessment of engineered nanomaterials, and protection of cultural and historic resources. DOE Order 450.1A also requires a more holistic approach to managing an environmental program. For example, surface water protection is looked at from a watershed perspective rather than only within the site boundary. When properly implemented, the EMS will enable the Laboratory to clearly identify and establish goals, develop and implement plans to meet the goals, determine measureable progress towards the goals, and make changes to ensure continual improvement.

Neither DOE Orders 450.1A or 430.2B nor Executive Order 13423 requires an organization's EMS to meet a recognized standard, such as the ISO 14001:2004(E), Environmental Management Systems Requirements with Guidance for Use. However, DOE Order 450.1A requires that the EMS reflect the 
elements and framework found in the ISO 14001 standard or equivalent. Section 3 of this Plan describes how each one of the eighteen elements in the ISO Standard is addressed, including reference to any procedure, plan, or process that implements these elements.

This Plan was prepared in accordance with LBNL's document management and control policy, which is stated in Section 5.08 of the Regulations and Procedures Manual ${ }^{11}$ (PUB-201) and more fully presented

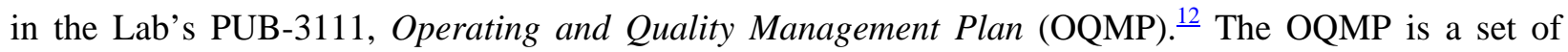
operating principles, requirements, and practices used to support LBNL organizations in achieving reliable, safe, and quality performance in their work activities. LBNL's EMS is listed as one of the management systems and process controls in the OQMP. The OQMP applies to all LBNL organizations.

The OQMP also provides commitment by LBNL's senior leadership to the EMS Plan and its implementation with the following statement:

"The Director of the Office of Institutional Assurance (OIA) is the senior LBNL manager who has the responsibility and authority to develop, implement, assess, and improve the LBNL Operating and Quality Management Plan”.

The Berkeley Lab EMS must be validated by the DOE Berkeley Site Office.

\subsection{COMPLIANCE-BASED APPROACH}

Consistent with the policy and directive of the Executive Order to conduct activities in both an environmental and fiscally sound manner, LBNL has developed and implemented a compliance- and performance-based EMS.

This Plan takes a systematic approach to ensuring protection of the environment and public health by compliance with federal, state, and local regulations and by environmental stewardship activities that are well-managed and provide business value. The EMS employs tailored approaches that accomplish DOE objectives in a manner that is most appropriate to the particular conditions and circumstances at the LBNL site. Accordingly, the EMS is based on the work, the environment in which the work is performed, and the hazards or impacts associated with the work at Berkeley Lab.

The Contractor Requirements Document (Attachment 1) of DOE Order 450.1A identifies items that the EMS must address. Items relevant to a compliance-based approach are discussed in this section. Those relevant to a performance-based approach are discussed in Section 2.3. The status of both compliancebased and performance-based programs is reported annually by Berkeley Lab in their Site Environmental Report $^{\underline{13}}$ (SER) for the calendar year. Sections listed beside the item refer to the section of the Contractor Requirements Document. 


\section{Environmental Compliance Management Plan (Section 1a(4)):}

Summarizing this requirement from the Order, each compliance management plan shall include the following essentials:

- A clear, sustained, and up-to-date commitment by senior leadership to achieve and maintain environmental compliance

- Clearly articulated roles and responsibilities related to environmental performance at all levels to ensure accountability for less than desired environmental performance.

- Implementation of an environmental compliance review and audit program that identifies compliance needs and possible root cause of non-compliance.

- Integration of compliance management system information and resource allocation procedures to ensure that audit findings and possible non-compliance root causes are tracked and addressed, including allocation of funding.

The overarching elements to achieve these requirements are found in the LBNL Integrated Environment, Health, and Safety Management Plan. Specific references include Section 4.2, ES\&H Policy Statement, Section 5, ES\&H and Assurance Organization Responsibilities, Services, and Interfaces, and Section 11, Evaluating and Resolving Non-compliances, which direct senior leadership to achieve safety and environmental compliance, identify broader organization roles and responsibilities, and establish review and corrective action for non-compliances, respectively. Chapter 11 of PUB-3000, Environmental Protection, further provides the specific environmental policy, program descriptions, and roles and responsibilities related to environmental compliance. The specific environmental compliance review and audit program is discussed in the Environmental Compliance Audit \& Assessment Program ${ }^{14}$ (ECAAP) Manual (See Section 3.18 of this Plan, Audits and Appraisals). The scope of this audit program is based on the legal and other requirements applicable to Berkeley Lab as discussed in Section 3.4 of this Plan.

Ambient Air Quality Standards (Section 1b(2)(a)):

The Bay Area Air Quality Management District is the regulatory agency responsible for developing State Implementation Plans designed to attain and maintain National Ambient Air Quality Standards. LBNL's program to conform to these standards is described in subchapter 11.3.2 (Air Emissions) of PUB-3000. Chapter 3 (Environmental Monitoring Regulatory Requirements) of the Environmental Monitoring Plan provides information on how LBNL's monitoring and surveillance activities conform to air quality standards.

Surface Water Protection (Section 1b(2)(b)):

Surface water protection is managed by LBNL's stormwater management program. Implementation of a watershed approach for surface water protection is detailed in the sitewide Storm Water Pollution Prevention Plan. This program is also described in subchapter 11.3.11 (Storm Water Discharges) of 
PUB-3000. Additional supporting information on this program is provided in the Environmental Monitoring Plan and the Alternate Storm Water Monitoring Plan.

Groundwater Protection (Section 1b(2)(c)):

Berkeley Lab’s Environmental Restoration Program manages implementation of a site-wide approach for groundwater protection. Subchapter 11.3.6 (Contaminated Soil and Groundwater Management) in PUB$\underline{3000}$ discusses the groundwater protection program, including controls necessary to avoid impacting this environment. This subchapter also provides links to various important Environmental Restoration Program documents. The Environmental Monitoring Plan includes some discussion on groundwater cleanup and protection measures.

Other natural resources, including biota (Section $1 \mathrm{~b}(2)(\mathrm{d}))$ :

Protection of other natural resources, including biota, is outlined in the subchapters 11.3.4 (Environmental $\underline{\text { Radiological Dose Assessment) and 11.3.5 (Environmental Monitoring) of PUB-3000. }}$

Engineered Nanomaterials (Section $1 \mathrm{~b}(2)(\mathrm{e}))$ :

The field of nanoscience and nanotechnology is relatively young, with regulatory requirements in the formative stage. Berkeley Lab takes a proactive approach to assessing the hazards of engineered nanomaterials and implementing appropriate ES\&H controls is provided in LBNL's Chemical Hygiene and Safety Plan. Controls address training, engineering and administrative controls, personal protective equipment, waste disposal, and emergency procedures for spills.

Wildland Fire Management (Section 1b(3)):

The LBNL site location in the urban/wildland interface makes it susceptible to wildland fires, especially during late summer and early fall. Berkeley Lab's efforts to protect site resources from wildland fires are managed through its Emergency Preparedness Program and described in its Master Emergency Program Plan. Reference to this plan and other useful information on planning relevant to Berkeley Lab personnel for emergencies in general and wildland fire in particular is found in chapter 9 (Emergency Management)

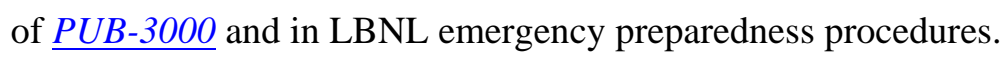

\section{Cultural Resources (section 1b(4)) and Historic Properties (Section 5):}

As one of the oldest facilities in the DOE complex and being located on land that had never previously been developed, cultural resources and historic property reviews are an important and routine evaluation for new development projects and long range planning at LBNL. An excellent summary on the history of the Laboratory, the range of historical and archeological resources that exist, the regulatory requirements affecting these resources, and measures LBNL is taking to protect these resources is found in Section IV.D (Cultural Resources) of the Environmental Impact Report for LBNL's 2006 Long-Range Development Plan. 


\section{Environmental and Effluent Monitoring (section 1b(5)):}

Berkeley Lab’s environmental and effluent monitoring program covers numerous environmental media. Its purpose is to ensure that activities at the site are conducted in a manner that will protect and maintain environmental quality, and demonstrate compliance with regulatory standards, DOE environmental protection policies, and supports environmental management decisions. The information gathered is reported annually in the Laboratory's Site Environmental Report, and in certain cases, reports to regulatory agencies. Environmental monitoring activities are described in several documents; the Environmental Monitoring Plan and subchapters 11.3.4 (Environmental Radiological Dose Assessment) and 11.3.5 (Environmental Monitoring) of PUB-3000.

\section{Safe Alternatives to Ozone-Depleting Substances (Section 3):}

LBNL implemented an aggressive program to phase out ozone-depleting substances in the 1990's. That program concentrated on eliminating Class I ozone-depleting substances either by replacement with newer equipment or retrofitting existing equipment with an acceptable alternative substance. The program also included a component restricting the procurement of specific materials designated as ozone-depleting substances. The restricted items component remains in place today as part of Berkeley Lab's Procurement and Property Management group, who maintains a Restricted Items list in accordance with the terms of the operating contract between the Department of Energy and the Regents of the University of California (Contract No. DE-AC02-05CH11231). $\frac{15}{}$ Ozone-depleting substances are considered a Special Treatment Item, which requires special approvals, controls, or safety measures.

\section{Chemical Emergency Planning, Release, and Reporting (Section 4):}

Berkeley Lab takes a two-fold approach to chemical emergency planning, release, and reporting. First, its Hazardous Materials Business Plan ${ }^{16}$ includes a list of all hazardous materials present in amounts exceeding the state's aggregate threshold quantities (i.e., 208 liters [55 gallons] for liquids, 227 kilograms [500 pounds] for solids, and 5.7 cubic meters [200 cubic feet] for compressed gases) per building. The plan includes a sitemap as well as summaries of emergency plans, procedures, and training. The plan is updated and submitted to the City of Berkeley annually.

Second, Community Right-to-Know Act regulations (40 CFR 372 ${ }^{17}$ ) require LBNL to annually evaluate its releases of toxic chemicals and report to the U.S. Environmental Protection Agency if releases exceed thresholds cited in the regulation.

The status on both requirements is reported each year in LBNL's Site Environmental Report.

\subsection{PERFORMANCE-BASED APPROACH}

The performance-based approach applies the elements of ISO 14001 in a manner that provides real and tangible business value, rather than an approach that applies all the requirements of an ISO 14001-type of EMS, regardless of their value. This approach allows the Berkeley Lab to focus resources on those 
activities that have a more valuable and stronger environmental benefit and to maintain the current strengths of the environmental compliance programs. Performance of the EMS is measured by multiple methods and involves various internal and external organizations.

In terms of implementing the EMS plan, LBNL establishes and maintains Environmental Management Programs after evaluating significant environmental aspects and impacts. The EMPs are designed to achieve the goals and objectives of sustainable practices identified in DOE Orders 450.1A and 430.2B that originated in Executive Order 13423, the Energy Policy Act of 2005, the Energy Independence and Security Act of 2007, and DOE's Transformational Energy Action Management initiative. Sustainable practices of particular interest to DOE are:

- Improvement in energy efficiency and reduction in greenhouse gas emissions,

- Use and on-site generation of renewable energy,

- Reduction in water consumption,

- Acquisition of recycled-content and biobased-content materials (i.e., environmentally-preferable products),

- Reduction of the use and disposal of toxic and hazardous chemicals and materials,

- Pollution and waste prevention/diversion and recycling programs,

- High performance and sustainable buildings,

- Vehicle fleet management and alternative fuels consumption, and

- Electronics stewardship.

Berkeley Lab’s EMS implements these practices where they are applicable (i.e., provide tangible business value). More on EMPs is discussed throughout Section 3, Program Elements.

In terms of oversight reporting on efforts to continually improve the performance of its EMS, LBNL conducts operational assessments to identify pollution prevention and sustainable practice opportunities. Using self-assessments performed by the various divisions that evaluate environmental and safety performance, LBNL's Office of Contract Assurance (OCA) annual reports on the effectiveness of the Lab's ISMS through the ISMS assessment process (See Integrated EH\&S Management Plan, subsection 6.7.1.5, An Annual Assessment of LBNL's ISMS is Conducted).

A more important role played by OCA for measuring performance of the EMS program is through administering the Lab-wide Performance Evaluation Measurement Plan ${ }^{18}$ (PEMP), which is a reporting obligation within the operating contract between DOE and the Regents of the University of California. Measures explicitly targeting EMS performance are included in the PEMP for the Environment, Health, and Safety (EH\&S) Division as well as the PEMP for the Facilities Division. These measures set targets and establish scoring gradients used to grade the EMS's annual performance. The EMS PEMP is efficiently structured to report metrics that are already required elsewhere, although not accounted for 
elsewhere because of differing reporting objectives (see EMS Data Call discussion that immediately follows). PEMPs, both individual and collectively, play a critical role in the annual scoring by DOE of LBNL's overall performance, which directly affects the status of the operating contract.

External reporting on EMS performance is governed by two federal requirements; the Pollution Prevention Tracking and Reporting System, and the EMS Data Call. Reporting is based on fiscal year. Reporting is required of all federal agencies and their contractors (e.g., Berkeley Lab). The federal government's Office of Management and Budget oversees the reporting in its role of administering the requirements of Executive Order 13423.

The Pollution Prevention Tracking and Reporting System obtains information from Berkeley Lab on waste prevention, pollutant release reduction, toxic chemical use reduction, environmentally preferable purchasing, recycling, electronics stewardship, and other pollution prevention accomplishments.

The EMS Data Call follows an established set of metrics that are set at the federal level and apply to all federal agencies. Metrics may change from year to year. LBNL's EMS program manager and the DOE BSO counterpart concur on reporting grades for each metric.

DOE expects that compliance and performance-based requirements of Order 4501.1A also apply to LBNL's subcontractors. Compliance with applicable environmental regulations has long been a contractual obligation of subcontractors. Requiring sustainable practices of subcontractors is an evolving process. LBNL has identified contract types that are subject to EMS performance-based consideration. Of the nearly 80 types of contracts issued by LBNL, it is estimated that about $60 \%$ will be affected. LBNL presently has the option of including sustainable practice clauses in solicitations and subcontracts involving U.S. Environmental Protection Agency-Designated Items (i.e., a product that is or can be made with recovered material), environmentally preferable products and services, energy-consuming products listed in the ENERGY STAR ${ }^{2}$ or Federal Energy Management Programs, and USDA-designated biobased products. An existing EMP (Procurement of Goods and Services) tracks the Laboratory's overall annual use of energy efficient and recycled material products, including that reported by subcontractors. A near-term goal of Berkeley Lab's EMS to improve the coverage of requiring sustainable practices for subcontractors is for the Procurement and Property Management Department to modify prescribed language that will be used in appropriate new or reissued contracts.

Also related to subcontractor performance, at present, LBNL does not have tenants and has one concessionaire that performs activities affecting environmental, energy, and transportation management. The concessionaire is a vendor providing food service at the cafeteria. Cafeteria activities are currently addressed in a current EMP for Solid Waste Generation (diversion). Future additional concessionaire activities at Berkeley Lab will be considered at the appropriate time for inclusion in a performance-based EMP. 


\subsection{GOALS}

The goals of the LBNL EMS are four-fold:

1. Comply with all applicable environmental protection, public health, and resource conservation requirements.

2. Prevent pollution, minimize waste, and conserve natural resources.

3. Correct environmental hazards and cleaning up existing environmental problems, and

4. Continually improve the Laboratory’s environmental performance in a cost-effective manner while supporting the overall mission of the Laboratory.

A continual cycle of planning, implementing, evaluating, and improving processes and actions is followed to achieve these EMS goals (see the diagram below).

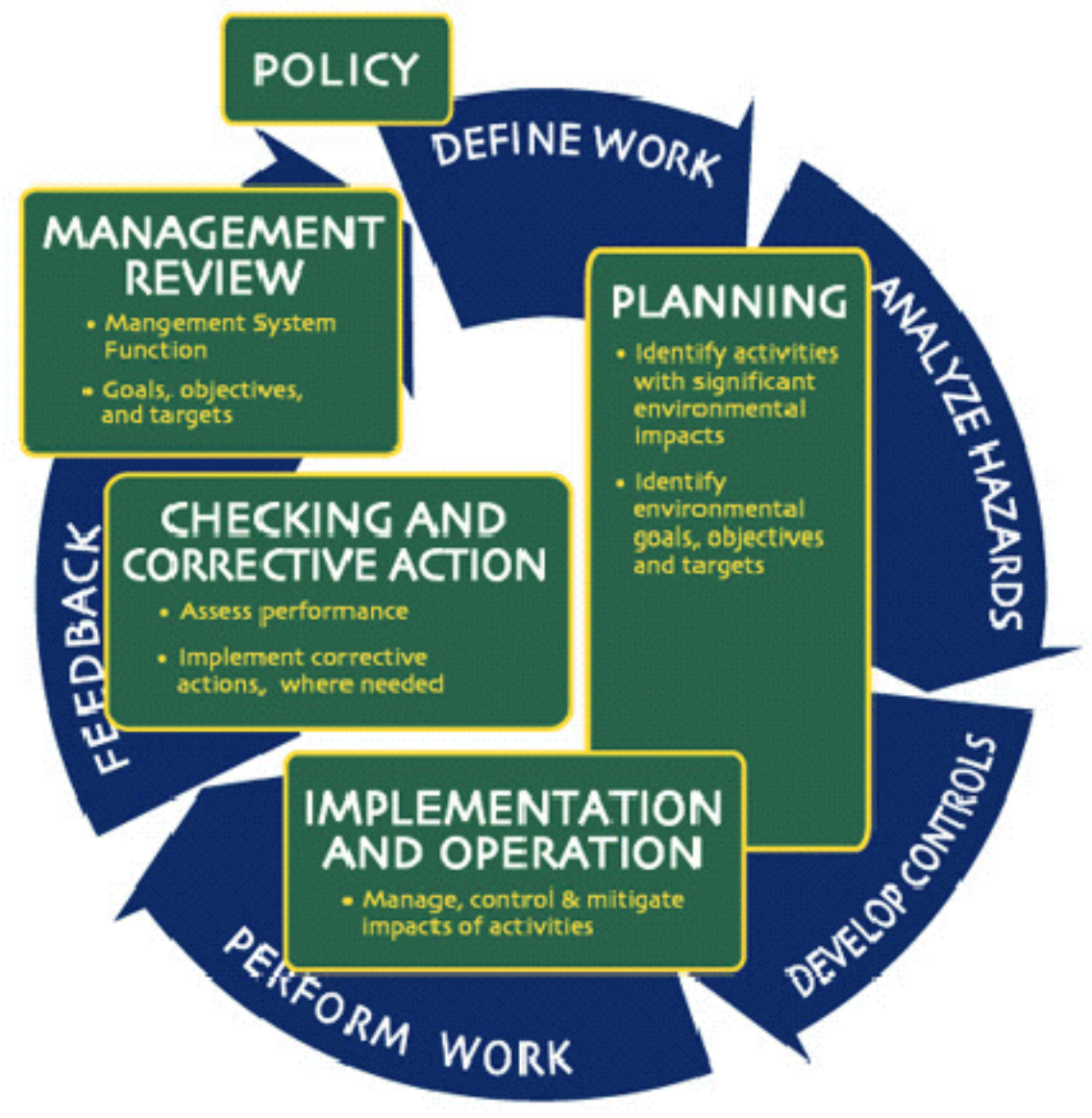

\section{$2.5 \quad$ INTEGRATION OF EMS WITH ISMS}

Berkeley Lab has integrated this EMS with the Integrated Safety Management System. To the extent that it is practical, existing ISMS processes are used to support environmental performance improvement and 
compliance management. Where that is not the case, new processes will be developed to support LBNL's EMS. These processes will also be integrated with the LBNL ISMS.

Both the EMS and ISMS strive for continual improvement, through a plan-do-check-act cycle. This cycle calls for defining the scope and purpose of the system, followed by a planning (Plan) step to develop programs and procedures that must then be implemented (Do). Once implemented, programs must be assessed (Check) and any problems corrected (Act) to improve the effectiveness of the management system and to achieve improved environment, safety, and health performance.

Table 1 shows the parallels between the five EMS top-level elements and ISMS core functions.

Table 1. Five EMS Top-Level Elements and ISMS Core Functions

\begin{tabular}{|c|c|c|}
\hline \multicolumn{2}{|c|}{ Environmental Management System } & Integrated Safety Management System \\
\hline & Policy & \\
\hline PLAN & Planning & Analyze Hazards \\
\hline DO & Implementation and Operation & Develop \& Implement Hazard Controls \\
\hline CHECK & Checking and Corrective Action & Provide Feedback and Continuous Improvement \\
\hline ACT & Management Review & Annual ISMS Review \\
\hline
\end{tabular}

\subsection{GAP AND STRATEGIC ANALYSIS}

Prior to the development of the initial LBNL EMS Plan, Berkeley Lab performed a gap and strategic analysis in fiscal year (FY) 2002. Existing programs and systems were reviewed that meet or correspond to an ISO 14001 EMS-required element. Relevant LBNL documents were reviewed, and relevant program managers were interviewed. Gaps were identified between the existing programs and systems, and each EMS element. Potential actions, that were required to address each gap, were identified, and the significance of each element for assuring environmental compliance and improving environmental performance was evaluated. Then, an implementation strategy was developed to maximize the use of existing systems.

Under then DOE Order 450.1, it was determined that an effective environmental management system could be constructed with the more valuable components of ISO 14001, using existing elements of the LBNL ISMS and focusing on environmental performance improvement and compliance management. The LBNL EMS would not pursue activities that have little value for improving environmental performance, such as the extensive documentation involved in connecting, summarizing, and describing existing LBNL activities that would be required for strict adherence to the ISO 14001 standard. While all elements of the ISO 14001 standard require documentation of procedures that are effective in managing and controlling associated activities, some are less critical for achieving focused improvement in environmental performance. Thus, a performance-based approach was developed that allows Berkeley Lab to focus its limited resources on improvement activities associated with more valuable and stronger environmental benefits. 
The LBNL EMS has evolved over time with improvements coming from experience gained in implementing the Plan as well as from changing requirements, including approval of Order 450.1A in June 2008. The philosophy of the approach continues to leverage on, and integrate with, systems and approaches that are already in place. For example, since the ISMS program is an effective and documented system, it has served as an excellent platform for building the LBNL EMS. All elements of the ISO 14001 standard are addressed in this EMS Plan, though LBNL continues to focus its resources on the key EMS elements that provide the most value. 


\section{0 \\ Program Elements}

Consistent with the framework of ISO 14001, implementation of the LBNL EMS program addresses the following eighteen elements:

1. General requirements

2. Environmental policy

3. Environmental aspects

4. Legal and other requirements

5. Objectives, targets, and Environmental Management Programs

6. Structure and responsibility

7. Training, awareness and competence

8. Communication

9. Documentation

10. Document control

11. Operational control

12. Emergency preparedness and response

13. Monitoring and measurement

14. Evaluation of compliance

15. Nonconformance, corrective action, and preventive action

16. Records

17. Audits and appraisals

18. Management review

\subsection{GENERAL REQUIREMENTS}

The intent of this element is to establish, document, implement, maintain, and continually improve an organization's EMS through the remaining elements of the ISO 14001 standard. The scope of LBNL's EMS covers the activities of all divisions as noted by reference to the various institutional documents throughout this chapter (e.g., Regulations and Procedures Manual; Integrated Environment, Health and 
Safety Management Plan; PUB-3000; PUB-3111). Activities in the context of this EMS include those at both onsite and offsite locations.

\subsection{ENVIRONMENTAL POLICY}

The environmental policy is contained within the overall environment, safety, and health (ES\&H) policy that is found in the Regulations and Procedures Manual and the Integrated Environment, Health and Safety Management Plan:

"It is the policy of Lawrence Berkeley National Laboratory to perform all work safely with full regard to the well-being of workers, guests, the public, and the environment."

The environmental portion of this policy is further detailed in Chapter 11 (Section 11.1) of the Berkeley Lab Health and Safety Manual (PUB-3000). LBNL is committed to the following policy:

1. Complying with applicable environmental, public health, and resource conservation laws and regulations.

2. Preventing pollution, minimizing waste, and conserving natural resources.

3. Correcting environmental hazards and cleaning up existing environmental problems, and

4. Continually improving the Laboratory's environmental performance while maintaining operational capability and sustaining the overall mission of the Laboratory.

Implementing this policy relies on the following core safety values found in Berkeley Lab’s ISMS:

- The institution demonstrates a strong commitment to safety by integrating safety into all facets of our work.

- Managers and supervisors are actively involved and demonstrate leadership in performing work safely.

- Individuals take ownership for safety and continually strive to improve.

- Individuals demonstrate an awareness and concern for the safety of others.

As stated in Berkeley Lab's Integrated Environment, Health \& Safety Plan, in accordance with DOE Policy 450.4 Safety Management System Policy, whenever the term safety is used, “...the term safety is used synonymously with environment, safety and health (ES\&H) to encompass protection of the public, the workers, and the environment." Clause I.074 of Contract 31 expands the definition of safety by "including pollution prevention and waste minimization." Contract 31 is the operating contract between the Department of Energy and the Regents of the University of California. It is also referred to as Contract No. DE-AC02-05CH11231. 


\subsection{ENVIRONMENTAL ASPECTS}

Identification and prioritization of significant environmental aspects is a key part of the systematic planning involved in environmental programs designed to protect public health and the environment, prevent pollution, and conserve resources. Environmental protection and pollution prevention programs are outlined in Chapter 11 of PUB-3000. Specific information on LBNL integration of pollution prevention into the planning process is provided in subsection 11.3.13, Waste Minimization and Pollution Prevention. The EMS Core Team, which includes members from various divisions across the Laboratory charged with administering important elements of the EMS, addresses such areas as the procurement of energy-efficient, water-conserving, and environmentally-preferable products, the development of sustainable practices that conserve natural resources, and the implementation of sustainable building designs and practices.

The Core Team identifies environmental aspects resulting from LBNL operations. Environmental aspects are considered activities or services that may produce a change to the environment, whether adverse or beneficial, wholly or partially, immediately or gradually. Consideration is given to activities involving pollution prevention, waste generation and recycling, emissions and discharges to the environment, material and resource use, land and building development and use, energy and water conservation, and transportation.

A list of environmental aspects is maintained that aids the Core Team in selecting significant issues to focus on each year. Attention is given to those aspects that will provide the most potential value toward improving Berkeley Lab’s environmental performance, compliance effectiveness, and sustainability practices. Additional environmental aspects are considered in subsequent years using the routine EMS goal-setting approach.

The Core Team meetings include detailed discussion of Berkeley Lab’s routine activities and services, such as research, engineering, maintenance and operations, administration, transportation, and construction. Emergency response and catastrophic events may also be discussed. An extensive list of environmental aspects/impacts is maintained and reviewed at least once each year. Executive and DOE Orders, and federal, state and local agency laws and regulations are reviewed for developing Berkeley Lab's environmental aspect/impact inventory list. An updated worksheet of these aspects/impacts is provided to each Core Team member for further evaluation. The worksheet is revised based on input from team members.

From this inventory worksheet, the Core Team determines which aspects are most significant. Significant aspects are evaluated relative to the framework of environmental impacts and objectives. The Core Team considers the life cycle of the Laboratory's activities or services and their potential impacts on the biosphere. Those aspects that are regulated by DOE or other regulatory agencies may be given greater 
emphasis. In addition, the Core Team uses the following (unranked) factors to shape its decisions on the significance of an aspect:

- Severity

- Impact on Laboratory's mission

- Duration

- Probability of occurrence

- Cost

- Effect on public image

- Potential legal exposure, and

- Potential for improvement.

Each aspect/impact is given a numeric rating based on a 3-tiered scoring system: high (3), medium (2), and low (1). Average scores and overall ratings for each aspect/impact will be determined and used to provide a starting point for the significance determination. Before this list is finalized, further evaluations of these identified aspects/impacts by the Core Team and other related employees will be performed. The Core Team may determine that additional information is needed to evaluate a particular product or activity; the team leader will assign the responsibility for collecting that information to an appropriate member. In these cases, selection of these significant aspects will not be based on the overall ratings, but on subsequent evaluations and Core Team discussions. The EMS Core Team is further described in the EH\&S Procedure 271, EMS Implementation (Core) Team.

The process of identifying environmental aspects and impacts and determining their significance is further described in EH\&S Procedure 272, Identification of Significant Environmental Aspects and Impact for the EMS.

\subsection{LEGAL AND OTHER REQUIREMENTS}

LBNL's Contract (No. DE-AC02-05CH11231) between DOE and the Regents of the University of California contains the official language and provisions that provide the legal basis for all Laboratory activities. Specifically related to environment, safety, and health standards, Appendix $I^{19}$ of the contract contains a list of all the laws, regulations, standards, orders, policies, and procedures that are applicable to LBNL, based on the specific hazards and activities found at the Laboratory. These standards are referred to as the Environment, Safety and Health Standards Set for LBNL, formerly called the Work Smart Standards Set. 
The process of identifying and maintaining the set of environment, safety and health standards that are applicable to LBNL is defined by the Change Management Process, which is a critical component of the Laboratory's ISMS. This process provides assurance that employees, the public, and the environment are adequately protected, and also describes how LBNL and the DOE Berkeley Site Office integrate their change management efforts for the ES\&H Standards Set.

Additional information regarding LBNL legal requirements and the Change Management Process can be found in Section 10, "Standards and Requirements", of the Integrated Environment, Health and Safety Management Plan.

\subsection{OBJECTIVES, TARGETS, AND ENVIRONMENTAL MANAGEMENT PROGRAMS}

\section{Objectives and Targets}

Objectives and targets are established based on the analysis of significant aspects and impacts. The EMS Core Team reviews the LBNL mission, long-term goals and strategic plans to determine if the objectives are consistent with these goals. Through the use of appropriate metrics, progress is measured toward achieving objectives and targets. The metrics are an essential piece of information used in appraisals, audits, and management reviews of the EMS. The metrics serve as the basis for action and for continual improvement.

The EMS Core Team may also solicit the views of parties external to the team. These parties may include DOE and other LBNL organizations, such as the Public Affairs office, to determine whether additional objectives are needed to address the views of interested parties.

All significant aspects are reviewed at least annually by the Core Team. If necessary, updated objectives and targets are established for each significant aspect. The Core Team reviews all environment, safety, and health goals to determine if additional objectives need to be established. Objectives and targets should be consistent with the Laboratory's policies and plans. Objectives are further categorized into one or more of the following areas:

- “C” - Control/Maintain - continued ongoing control and compliance with regulations and/or policies, guidelines and procedures.

- “I” - Improve - stated ongoing improvement actions already established or readily definable.

- "S" - Study/Investigate - requires investigation of potential alternatives for improvement including technology and process changes.

The Core Team reviews objectives for technological, financial, operational, and business parameters. They evaluate various options for meeting objectives, taking into consideration the Laboratory's resource and mission constraints, along with goals and time periods that are realistic to achieve the established targets. 
The objectives and targets are designed to consider site-specific goals, plus contribute toward the pollution prevention and energy-efficiency goals set by DOE, provided such goals are technically and financially feasible.

Additional information regarding objectives and targets can be found in EH\&S Procedure 273, Environmental Management Programs of the EMS. Additional information on site-specific goals is provided both in the next section, Environmental Management Programs, and on the EMS website.

Environmental Management Programs

For each significant aspect selected, the Core Team develops an EMP, appoints a leader, and establishes objectives and targets. The EMP leader may organize a task force to develop and implement this program. Using the objectives and targets, the Core Team establishes goals and strategies for the EMP, actions to achieve goals, identifies resource needs, develops procedures, metrics, or techniques, and sets up schedules. Each EMP typically follows a general work breakdown structure and may have multiple tasks or actions, and each task may employ specified procedures or techniques that must be developed, implemented, or used in order to achieve the objective and target. The level of detail of the work breakdown structure is tailored to the complexity and number of LBNL groups involved with implementing the EMP. A program schedule is typically prepared to help the EMP leader track the status of various EMP-related actions.

Periodically during the year, each EMP leader will present the progress results to the Core Team. The Core Team will monitor the progress of each EMP, make suggestions and comments, identify potential problems, and provide additional support when necessary. The Core Team meeting minutes will document EMP activities.

As with Objectives and Targets, additional information regarding EMPs can be found in EH\&S Procedure 273, Environmental Management Programs of the EMS. The current set of EMPs is located on the EMS website.

\subsection{STRUCTURE AND RESPONSIBILITY}

Successful implementation of this EMS requires varying degrees of commitment from all Berkeley Lab employees and subcontractors. Policy statements in several documents that have been previously mentioned in this Plan establish expectations for all to follow responsible and sustainable environmental practices in their work activities. Section 3.8 describes the various means by which the EMS program attempts to communicate these expectations to the Laboratory community as well as further educate the community on environmental management and sustainable practices.

The majority of the key roles and responsibilities are administered by a relatively small group of Berkeley Lab individuals:

- Senior management commitment to the EMS is the responsibility of the Director of the Office of Institutional Assurance as stated in the OQMP. 
- Annual management review responsibilities are the function of the Director of Environment, Health, and Safety. The director also approves the EMS Plan and its implementing procedures.

- Internal auditing of the EMS is performed annually with an assessment by the Office of Contract Assurance of the OIA Division.

- Quarterly environmental compliance auditing is the responsibility of the Environmental Services Group of the EH\&S Division.

- A third-party external audit by a qualified auditor will be performed at least once every 3 years to validate that the EMS is being implemented according to this plan.

- Remaining responsibilities for implementing the EMS rest largely with some or all members of the Core Team.

Sections 3.14 and 3.17 provide a more in-depth discussion on compliance auditing and internal and external EMS auditing, respectively.

The EMS Core Team, lead by the EMS Program Manager, is largely responsible for implementing the program. The EMS Program Manager is a representative of the EH\&S Division and is responsible for team leadership. The Core Team currently consists of representatives from the EH\&S, Facilities, and Procurement organizations. Members of the team were selected for their knowledge of environmental management concerns, their organizational role, and the potential impact they can have on achieving the sustainability goals set forth by DOE in Orders 450.1A and 430.2B. As issues arise, other organizations may be consulted or brought into the team. Similarly, input from other groups (e.g., LBNL Safety Review Committee or Division Safety Coordinators) can be solicited through designated Core Team representatives. The composition of the Core Team is expected to change with time as the program evolves. A representative from the DOE Berkeley Site Office is invited to the meetings in order to maintain an operational awareness of EMS activities.

As noted earlier, the Laboratory's activities are reviewed and reassessed each year by the Core Team as a means of evaluating LBNL's performance under the EMS. This assessment provides useful information for setting new objectives and targets in subsequent years, updating the EMS plan, and identifying problems that can be corrected to improve productivity and environmental performance. When new activities are suggested for consideration, they are categorized into environmental aspects, followed by a review of the associated impacts and an evaluation of their significance. A subset of environmental aspects with significant impacts will be selected for improvement. Objectives and targets will be developed to address each significant impact. EMPs will be prepared by members of the Core Team to document actions necessary for reducing certain environmental impacts, responsibilities for each action, and associated target deadlines. Tasks in the work breakdown structure of the EMPs will be assigned to appropriate task managers, who may not be members of the Core Team. Periodically, the Core Team will meet to monitor performance in achieving objectives and targets. 
The EMS Program Manager convenes meetings, leads the team through design, implementation, and ongoing use of the EMS, and serves as the main liaison between the EMS team and LBNL senior management. Records (e.g., meeting minutes, presentations, worksheets, EMPs) and other document control matters are maintained by the EMS Program Manager. Records will be retained for an indefinite period, or as required under records-retention procedures.

\subsection{TRAINING, AWARENESS, AND COMPETENCE}

In LBNL's EMS approach, training is targeted and graded, commensurate with the EMS activity. Four types of training are planned as follows:

1. General EMS awareness

2. Comprehensive EMS awareness

3. EMS implementation

4. EMS auditor

The general EMS awareness training includes summary information about EMSs and LBNL's EMS approach. The target audience includes key LBNL senior managers and LBNL staff critical to the implementation of an EMP. In addition, training is included in EH\&S Course EHS0010, Introduction to $E H \& S$ at $L B N L$, to provide new staff with an awareness on how environmental concerns are part of the LBNL general safety and ISMS training. Employees are reminded in this training that the Plan-DoCheck-Act functions of ISMS also apply to mitigating the environmental impacts of their activities.

The Core Team members need the comprehensive level of EMS awareness to ensure their competence in developing and implementing the EMS. This is accomplished by single or multiple training sessions conducted by personnel experienced with the implementation of an EMS. These may be arranged in conjunction with the Core Team meetings or conducted as separate, dedicated training sessions. Topics discussed at the Core Team meetings also serve as an on-the-job training opportunity that is documented by meeting minutes. Core Team members are also encouraged to participate in the EMS implementation or auditing training courses offered by accredited consultants. Core Team members, key support staff, or EMP task force members may also participate in other related training classes or conferences on pollution prevention, waste minimization, sustainable development, green building, or green purchasing offered by the DOE, U.S. Environmental Protection Agency, or other organizations.

The EMS Program Manager is required to take a comprehensive EMS implementation course. This type of course provides substantial details about EMS concepts and elements by typically requiring 1 to 3 days of coursework.

LBNL staff performing internal reviews of the EMS program must complete a comprehensive EMS implementation course and additional coursework that provides substantial information about auditing a systems-based program. The additional coursework usually requires an additional day or two of instruction. 
Additional information regarding EMS training can be found in EH\&S Procedure 274, EMS Training.

\subsection{COMMUNICATION}

EMS communication is performed in a number of ways at Berkeley Lab, such as by publishing an annual Site Environmental Report, posting information on websites and lessons learned databases, preparing articles for Berkeley Lab publications, delivering presentations to specific LBNL groups, and offering access to an employee EH\&S concerns website.

Each year, LBNL prepares an integrated report on its environmental programs to satisfy the requirements of DOE Order 231.1A, Environment, Safety, and Health Reporting. ${ }^{20}$ The Site Environmental Report summarizes Berkeley Lab's environmental management performance, presents environmental monitoring results, and summarizes significant environmental programs for the previous calendar year. The SER is distributed on the EH\&S Environmental Services Group website in an area that has been established for accessing publically-available environmental documents. Compact Disk and printed copies of the SER are also available on request. An announcement in LBNL's daily electronic newsletter, Today at Berkeley $L a b$, is made whenever a new SER is posted on the website.

The Environmental Services Group (ESG) website also contains a link to important EMS documents, including the EMS Plan, the current set of EMPs, EMS fact sheets, internal assessments, and third-party audit reports. These web pages provide open access to LBNL staff, DOE, other regulatory agency staff, and community members. Similar to the SER, these web pages are accessible at the Laboratory's main webpage through its $\underline{\mathrm{A}-\mathrm{Z} \text { Index. }}$

Berkeley Lab's OCA manages a lessons learned and best practices database. Noteworthy developments in the EMS program can be posted to this database where LBNL personnel can review, or if requested, receive an automated notification of new EMS-related postings.

Whenever appropriate, articles on EMS topics are included in Berkeley Lab publications, such as Today at Berkeley Lab. Topics may be determined by EMS Core Team members based on EMP activities and challenges. Environmentally-related articles may also be submitted by the general Laboratory population. The Laboratory community can also learn more about EMS program activities through occasional presentations provided by a Core Team member to groups such as the Safety Review Committee and Division Safety Coordinators.

LBNL employees or external parties may communicate their concerns or interests over any ES\&H topic using a dedicated Environment, Health \& Safety Concerns website. Various options exist for leaving concerns or questions, including anonymous reporting. At this site, visitors will find a special electronic address that has been set up for receiving EMS-related concerns: ems@lbl.gov.

Communications within the DOE community is also important. While all members of the Core Team may exchange knowledge with colleagues at other DOE-funded facilities or at DOE offices, the EMS Program 
Manager is likely the one to have the most opportunities for these exchanges through participating in such forums as DOE's EMS Assistance Network where valuable lessons learned are shared between members.

The success of the EMS depends on ongoing and multiple lines of communication. These lines can vary depending on factors such as the level of environmental impact, the types of control, the degree in which an environmental concern vertically and horizontally permeates the organization, and the level of effort needed to promote environmental compliance or performance goals.

\subsection{DOCUMENTATION}

The EMS includes the following documentation:

- An EMS Plan that describes the scope and elements of the environmental management system and how it relates to the Laboratory's ISMS and ISMS processes.

- Six implementing procedures for the EMS Plan that provide additional information about the following activities: (1) establishing an implementation team, called Core Team, (2) identification of significant environmental aspects and impacts, (3) environmental management programs, (4) training, (5) assessments and audits, and (6) management review.

- EMPs for aspects with significant environmental impacts, including objectives and targets for addressing each impact.

- An Environmental Aspect and Impact Worksheet that provides a comprehensive list of environmental aspects shows how they were evaluated and which ones were considered significant.

- Audit and assessment reports from internal and external organizations.

- Other records including meeting minutes and attendance sheets, presentation materials, fact sheets, and training records.

Much of this information is available at the Laboratory's Environmental Management System website. In addition, in the second quarter of 2009, the Procurement and Property Management Department is expected to modify standard pro forma language for use in all new or reissued contracts to include requirements for implementing sustainable practice. This important aspect of improving the flow down requirements to contractors will be documented in the Regulations and Procedures Manual.

\subsection{DOCUMENT CONTROL}

EMS documents that are formally reviewed and approved for adequacy prior to issue are this EMS Plan, its five implementing procedures, and an audit and assessment manual.

This document, the EMS Plan, is prepared by the EMS Program Manager, reviewed by the Core Team members, and approved by the Director for the EH\&S Division. The current version of this Plan is posted 
on the EMS website. This Plan was prepared in accordance with LBNL's document management and control policy, which is stated in Chapter 5 of the Regulations and Procedures Manual.

The Plan's implementing procedures are also prepared by the EMS Program Manager and approved by the Director for the EH\&S Division.

These documents are reviewed and updated as necessary, based on the judgment of the EMS Program Manager. The EMS Program Manager also retains hardcopy versions of critical documentation. Electronic versions of essential and relevant documents are maintained in a centralized network location that is regularly backed-up for protection. As noted throughout this Plan, many of the key documents are kept on the LBNL EMS website. Documents are tracked by a date and revision number to maintain control.

\subsection{OPERATIONAL CONTROL}

Operational controls may be evaluated for those operations that are associated with the significant environmental aspects in order to determine if activities are conducted in a way that will reduce the adverse impacts associated with them. Documented procedures may be considered in situations where there are difficulties in achieving or maintaining environmental objectives and targets, or where the absence of such procedures may lead to deviations from LBNL's environmental policy.

\subsection{EMERGENCY PREPAREDNESS AND RESPONSE}

There are three principle documents that establish emergency preparedness and response policies and procedures at LBNL. They are:

1. Master Emergency Program Plan (PUB-533) $)^{21}$

2. Hazardous Materials Business Plan (PUB-836) ${ }^{22}$

3. Spill Prevention Control and Countermeasures Plan $\underline{23}$

The Master Emergency Program Plan establishes policies, procedures and an organizational structure for responding to and recovering from a major disaster at LBNL. This document was prepared and is maintained to meet DOE's contractor requirements in DOE Order 151.1B, Comprehensive Emergency Management System. $\underline{24}$

According to California regulation, facilities handling specific chemicals in excess of certain amounts must annually prepare a Hazardous Materials Business Plan and submit it to local administering agencies. As a federal facility, LBNL is exempt from this regulation but voluntarily prepares this plan and submits it to the City of Berkeley. The plan contains information about the amounts and locations chemicals are used as well as information about emergency plans and procedures. The current Hazardous Materials Business Plan is available from the EH\&S website by selecting the document at "EHS Quick Links". 
The Spill Prevention Control and Countermeasures Plan ${ }^{25}$ for the LBNL site contains policies and procedures for the safe storage and use of oil and for responding to oil spills. It was prepared and is maintained to meet federal and state regulatory requirements for these materials and practices.

\subsection{MONITORING AND MEASUREMENT}

LBNL has developed and implemented an environmental monitoring program to ensure that its activities are conducted in a manner that will protect and maintain environmental quality. The results of this program demonstrate compliance with requirements imposed by federal, state, and local agencies; confirm adherence to DOE environmental protection policies; and support environmental management decisions. The environmental monitoring program is implemented by the EH\&S Environmental Services Group and consists of four major activities:

1. Effluent Monitoring

2. Environmental Surveillance

3. Meteorological Monitoring

4. Pre-operational Monitoring

Further information can be found in the Environmental Monitoring Plan..$^{26}$

In addition to measuring and tracking associated with EMPs that was discussed earlier, environmental management activities are also monitored as a part of Berkeley Lab’s ES\&H self-assessment program. The self-assessment program is a formal, internal process used to evaluate ES\&H programs, policies, and processes. The process is designed to ensure that Laboratory work is conducted safely and with minimal adverse effects to workers (employees, participating guests, and subcontractors), the public, and the environment. The program is also the mechanism used to institute continual improvements to the Laboratory's ES\&H programs. It uses performance objectives and criteria based on the ISM core functions and guiding principles to evaluate the ES\&H performance, including environmental management performance. This type of assessment is not one of the audits or assessments directly associated with the EMS program, though information obtained by such a review may be relevant and beneficial to the EMS program.

Additional information about the Laboratory's self-assessment program can be found in the EH\&S SelfAssessment Program (PUB-5344). ${ }^{27}$

\subsection{EVALUATION OF COMPLIANCE}

Quarterly, LBNL's Environmental Services Group reviews programs under its purview through its Environmental Compliance Audit \& Assessment Program. The ECAAP was established to meet the requirements of DOE Order 450.1A, which calls for an environmental compliance audit program to monitor and improve compliance with environmental regulations. This program conforms to the legal and 
other environmental regulations identified in the ES\&H Standards Set discussed earlier in Section 3.4. Under the Order, the audit program must further identify compliance deficiencies, the root causes of noncompliance, and track deficiencies until properly addressed. Tracking of any findings is administered through use of the Laboratory's CATS. The ECAAP serves an additional purpose of satisfying the Laboratory's institutional technical assurance assessment requirements promulgated in the Environment, Safety and Health (ES\&H) Self-Assessment Program (LBNL/PUB-5344) and described by the ES\&H Technical Assurance Program (TAP) Manual (LBNL/PUB-913E). ${ }^{28}$ A report is prepared for each program audited under the ECAAP. All reports are submitted to the EH\&S Division Director prior to LBNL's OCA to fulfill the technical assurance assessment requirements.

\subsection{NONCONFORMANCE, CORRECTIVE ACTION, AND PREVENTIVE ACTION}

Environmental compliance inspections and reviews are conducted by a number of external organizations including:

- University of California Office of the President

- U.S. Department of Energy

- U.S. Environmental Protection Agency, Region 9

- California Department of Toxic Substances Control

- California Department of Public Health

- California Air Resources Board

- California Water Resources Control Board

- Regional Water Quality Control Board

- Central Contra Costa Sanitary District

- East Bay Municipal Utility District

- Bay Area Air Quality Management District

- City of Berkeley

Internal environmental assessments may also be conducted by Laboratory organizations under an ongoing self-assessment program briefly discussed in Section 3.13. Regularly scheduled internal assessments are conducted by LBNL's OCA and ESG. Further information on internal assessments is presented below in Section 3.17.

Issues, including findings and observations, from inspections, reviews, and assessments are documented in reports, adhering to the institutional requirements specified in the Laboratory's Issues Management Program. ${ }^{29}$ In response to findings, laboratory management develops action plans to correct the identified operational and management deficiencies as necessary. The plans include schedules for completing the 
corrective actions and can provide for regular reporting, as required, to the agency or office that conducted the appraisal until all deficiencies are closed out.

In order to facilitate the corrective action process, the Laboratory has implemented a facility-wide webbased system to track actions, called the Corrective Action Tracking System (CATS). It serves as a means for LBNL management to identify, track, and review resolution of institutional deficiencies. Significant EMS deficiencies, such as audit findings, must be entered into CATS. Less significant deficiencies, such as observations or recommendations to follow a best management practice, are entered into CATS at the discretion of the EMS Program Manager.

Further information regarding the Laboratory's policies and procedures regarding compliance reviews and the corrective action process can be found in Section 11, "Evaluating and Resolving Non-compliances", of the Integrated Environment, Health and Safety Management Plan.

\subsection{RECORDS}

Records management is a line-management function at Berkeley Lab. The Laboratory's Archives and Records Office assists line management in meeting its record management responsibilities. The Laboratory's policies and procedures for records management are described in the Regulations and

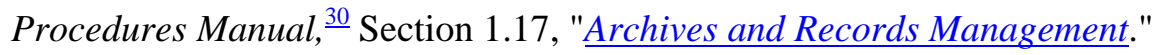

\subsection{AUDITS AND APPRAISALS}

\section{$\underline{\text { Internal Assessment }}$}

Annually, an internal assessment is performed of the EMS program and activities by LBNL's OCA. The internal assessors should be knowledgeable about EMS requirements under DOE Order 450.1A and familiar with the LBNL performance-based EMS. The review determines if the EMS activities conform to the requirements of the LBNL EMS program plan and if it has been properly implemented and maintained. The review may suggest corrective actions and opportunities for improvement. Additionally, the assessors may review the performance of the EMPs. The results of the internal review are discussed with the EMS Core Team, who determines what actions are necessary to address the assessment findings. In addition, the results of the internal assessment may also be presented to LBNL senior management.

\section{$\underline{\text { Validation Audit }}$}

On a three-year cycle, a third-party validation of the LBNL EMS program is required. The auditor(s) task is to determine if the EMS activities conform to the requirements of the DOE Order, LBNL EMS program policies, and if it has been properly implemented and maintained. A subject matter expert or team of experts knowledgeable of EMS requirements and experienced with the implementation of EMSs in research facilities performs this validation audit. A representative from the DOE Berkeley Site Office will be invited to participate as an observer on the team. It is anticipated that the length of the validation will be approximately 5 days, including both desk and onsite reviews. The findings will be presented to the 
EMS Core Team, who determines the appropriate set of corrective actions. In addition, the results of the validation audit may be presented to LBNL senior management and the DOE Berkeley Site Office. If the validation audit determines that there are significant weaknesses in the program, a special management review (beyond that described in Section 3.18) may be convened. As with internal assessments, all significant findings will be tracked using the Laboratory's CATS.

The internal assessment and validation audit processes are further described in EH\&S Procedure 275, EMS Assessments and Audits.

\subsection{MANAGEMENT REVIEW}

Annually, the EMS activities are reviewed by LBNL senior leadership. At a minimum, the EMS Program Manager will meet with the EH\&S Division Director and a representative from OCA to discuss one or more of the following topics:

- Significant environmental impacts

- EMP progress

- Candidate projects for addressing the significant environmental impacts

- Results of EMS internal assessments and external audits

- Recommendations for continual improvement in all areas related to the EMS.

Based on this review, top management at LBNL, which includes the EH\&S Division Director may determine the need to make changes to the EMS program seeking continual improvement. Factors such as improved assessment methodologies, or major changes to the facility's mission, products, and processes are considered in determining the need to make changes to the program.

The management review process is further described in EH\&S Procedure 276, Management Review of the EMS. 


\section{0 \\ References}

1. U.S. Executive Order 13423, Strengthening Federal Environmental, Energy, and Transportation Management (January 26, 2007).

2. U.S. Department of Energy, Environmental Protection Program, DOE Order 450.1A (June 4, 2008).

3. DOE O 430.2B, Departmental Energy, Renewable Energy and Transportation Management, (February 27, 2008).

4. U.S. Department of Energy, Safety Management System Policy, DOE P 450.4 (October 15, 1996).

5. Public Law 109-58, Energy Policy Act of 2005 (August 8, 2005).

6. Public Law 110-140, Energy Independence and Security Act of 2007 (December 19, 2007).

7. Lawrence Berkeley National Laboratory, FY2009 LBNL Sustainability Executable Plan (December 2008).

8. Lawrence Berkeley National Laboratory, Health and Safety Manual, PUB-3000, Chapter 11, Environmental Protection, http://www.lbl.gov/ehs/pub3000/CH11.html (March 2007).

9. Lawrence Berkeley National Laboratory, Integrated Environment, Health and Safety Management Plan, PUB-3180, http://www.lbl.gov/ehs/ism/ism 06.pdf (September 2007).

10. International Organization for Standardization (ISO) 14001:2004(E), Environmental Management Systems -Requirements with Guidance for Use, http://www.iso.org (November 2004).

11. Lawrence Berkeley National Laboratory, Regulations and Procedures Manual, PUB-201, http://www.lbl.gov/Workplace/RPM/R5.08.html (October 2008).

12. Lawrence Berkeley National Laboratory, Operating and Quality Management Plan, http://www.lbl.gov/DIR/OIA/assets/docs/OCA/About OCA/OQMP Rev10-7.pdf (October 2008).

13. Lawrence Berkeley National Laboratory, Site Environmental Reports, http://www.lbl.gov/ehs/esg/Reports/tableforreports.htm (current year).

14. Lawrence Berkeley National Laboratory, Environmental Compliance Audit and Assessment Program Manual (March 2009). 
15. U.S. Department of Energy, Contract between the United States of America and the Regents of the University of California, LBNL Contract No. DE-AC02-05CH11231, http://labs.ucop.edu/labprimecontracts/index.html (May 2005).

16. Lawrence Berkeley National Laboratory, Hazardous Materials Business Plan, (February 2008).

17. U.S. Environmental Protection Agency, Toxic Chemical Release Reporting: Community RightTo-Know, 40 CFR 372 (1988, as amended).

18. U.S. Department of Energy, Contract between the United States of America and the Regents of the University of California, LBNL Contract No. DE-AC02-05CH11231 Section J, Appendix B, http://labs.ucop.edu/labprimecontracts/LBNL/sections/section_j/lbnl_secj_app_b.pdf $\quad$ (October 2008).

19. U.S. Department of Energy, Contract between the United States of America and the Regents of the University of California, LBNL Contract No. DE-AC02-05CH11231 Section J, Appendix I, http://labs.ucop.edu/labprimecontracts/LBNL/esh std lbnl.pdf (November 2008).

20. U.S. Department of Energy, Environment, Safety, and Health Reporting, DOE Order 231.1A (1995, as amended).

21. Lawrence Berkeley National Laboratory, Master Emergency Program Plan (December 1, 2005).

22. Lawrence Berkeley National Laboratory, Hazardous Materials Business Plan (March 2007).

23. Lawrence Berkeley National Laboratory, Spill Prevention Control and Countermeasures Plan (October 2007).

24. U.S. Department of Energy, Comprehensive Emergency Management System, DOE Order 151.1B (October 29, 2003).

25. Lawrence Berkeley National Laboratory, Spill Prevention Control and Countermeasures Plan (October 2007).

26. Lawrence Berkeley National Laboratory, Environmental Monitoring Plan (February 2006).

27. Lawrence Berkeley National Laboratory, Environment, Safety, and Health Self-Assessment Program, http://www.lbl.gov/DIR/OIA/assets/docs/OCA/OCA ESH/PUB5344.pdf (September 2007).

28. Lawrence Berkeley National Laboratory, Technical Assessment Manual http://www.lbl.gov/DIR/OIA/assets/docs/OCA/OCA_ESH/ESH Technical Assurance Program Manual R1 Final.pdf, LBNL/PUB-913E (December 2008).

29. Lawrence Berkeley National Laboratory, Issues Management Program, http://www.lbl.gov/DIR/OIA/OCA/assurance-sys/IA/index.html 
30. Lawrence Berkeley National Laboratory, Regulations and Procedures Manual, PUB-201, http://www.lbl.gov/Workplace/RPM/R1.17.html (August 2006). 